ISSN: 0213-2087 e-ISSN: 2444-7080

DOI: https://doi.org/10.14201/shhcont382020175199

\title{
UNA NACIÓN MODERNA. \\ MASCULINIDADES ESPAÑOLAS POSTIMPERIALES FRENTE A GUINEA ECUATORIAL
}

\author{
A Modern Nation. \\ Post-imperial Spanish Masculinities \\ facing Equatorial Guinea
}

\author{
Sara SANTAMARÍA COLMENERO \\ Universidad de Aarbus (Dinamarca) ${ }^{1}$
}

Recibido: 15/04/2020 Revisado: 17/06/2020 Aceptado: 20/06/2020

RESUMEN: Este artículo analiza una serie de discursos sobre la nación española que, en las últimas dos décadas, representan España como una nación moderna en contraposición con su antigua colonia, Guinea Ecuatorial. Aborda, para ello, la interrelación entre los discursos nacionales y la categoría de género, que atraviesa una serie de obras ensayísticas y literarias ambientadas en la antigua colonia. Estudia los diferentes modelos de masculinidad que se han identificado con la nación española con el objetivo de defender su papel positivo y civilizador para el país africano, concebido como atrasado, cuyas gentes necesitarían de la tutela de la antigua metrópolis para avanzar en la senda del progreso. Identifica y analiza dos modelos de masculinidad: el arquetipo del explorador, que reactualiza un modelo de masculinidad colonial, y el del hombre cosmopolita homosexual.

Palabras clave: Nación española; modernidad; género; masculinidades; Guinea Ecuatorial.

1. Este artículo es fruto del proyecto «Cultural Memories of Spain's Violent Pasts: Literary Transfers, Colonialism in Africa and the Civil War» (DFF 4089-00171), financiado por la Unión Europea (Marie Curie Program, FP7) y el Danish Council of Independent Research. Agradezco a los informantes anónimos su lectura y comentarios sobre este texto. 
ABSTRACT: The article analyses a set of discourses about the Spanish nation that depict Spain like a modern nation compared to its ancient colony Equatorial Guinea, in the last two decades. It addresses the interrelation between national discourses and gender that informs a batch of essays and literary works set in the ancient colony. It studies different models of masculinity that have been identified with the Spanish nation to defend its positive influence and civilizing role for the African country. The last one has been conceived like an underdeveloped country and their people considered in need of the aid of the ex metropolis in order to progress. The paper identifies and studies two models of masculinity: the archetype of the explorer, which resignifies a colonial model, and the archetype of the cosmopolitan homosexual man.

Key words: Spanish nation; modernity; gender; masculinities; Equatorial Guinea.

Los debates sobre la modernidad de la nación española tienen una larga estela y en determinados períodos se han intensificado. A finales del siglo XIX, la pérdida de Cuba, Puerto Rico, Filipinas y Guam derivó en un cuestionamiento sobre la modernidad de una nación que se mostraba entonces incapaz de preservar sus últimas colonias. Durante la Guerra Civil española se enfrentaron formas diversas de concebir la nación que apelaban a modos distintos de comprender su modernidad. Cuarenta años más tarde, la transición de la dictadura a la democracia fue interpretada mayoritariamente como la salida de un largo período de decadencia nacional, la dictadura franquista, que terminaría con la entrada efectiva de España en la Unión Europea, en 1986. Tiempo después, en 1992, España acogió la celebración de los Juegos Olímpicos de Barcelona y la Exposición Universal de Sevilla, cuyo tema fue "La era de los descubrimientos» y que se clausuró el 12 de octubre, día de la Fiesta Nacional. Ambos acontecimientos fueron vividos como culminación de la entrada de España en el club de las naciones modernas $^{2}$. No obstante, los debates sobre la modernidad o retraso de España no se clausuraron, ni mucho menos. A lo largo de la primera década del siglo XXI, las polémicas sobre la memoria histórica y sobre cómo España debía afrontar el pasado traumático de la Guerra Civil y el franquismo, en comparación con otras naciones europeas, se articularon en términos de modernidad. Para algunos intelectuales, si España quería alcanzar una verdadera modernidad, como Alemania — país que había renegado públicamente del nazismo e incorporado el Holocausto a su historia nacional— debía hacer las cuentas con el pasado y restituir la Segunda República como antecedente de la democracia recuperada. Para otros, sin embargo, España alcanzó la modernidad con el paso a un régimen democrático. En términos de modernidad se articularon también las reivindicaciones que el movimiento de los indignados realizó en 2011, que

2. Sobre el debate de la modernidad de la nación española véanse, por ejemplo, los siguientes trabajos: BALFour, Sebastian y Alejandro Quiroga: España reinventada. Nación e identidad desde la Transición, Barcelona: Península, 2007; Delgado, Luisa Elena: La nación singular. Fantasías de la normalidad democrática española (1996-2011), Madrid, Siglo XXI, 2015. 
se condensaban en una relectura de la democracia que incluía más derechos sociales y solicitaba una transición verdadera que terminase con el denominado «régimen del 78", concebido como una extensión de la dictadura en los diversos ámbitos: político, social, económico y cultural.

La segunda década del siglo XXI ha estado atravesada también por el debate sobre la modernidad de la nación española. A ese debate han contribuido una serie de discursos y prácticas culturales que han puesto en circulación relatos sobre un pasado considerado olvidado: la colonización por parte de españoles de territorios pertenecientes hoy en día a Guinea Ecuatorial, en el África subsahariana. Estos relatos participan del proceso siempre inacabado de construcción de la nación y lo hacen en este caso para reivindicar la labor de España como potencia colonizadora y civilizadora. La nación española afirma así su modernidad en contraposición con el pueblo ecuatoguineano, que se presenta como una nación carente de cultura, que necesita desarrollarse y modernizarse a imagen y semejanza de España.

Los discursos que defienden la modernidad de España explotan la comparación entre esta y Guinea Ecuatorial para reforzar su argumentación. Lo hacen además a través de la identificación de España con diversas concepciones de la masculinidad, que comparten todas ellas el afán por conocer territorios desconocidos desde una posición de superioridad identificada con la modernidad occidental.

En este artículo analizo dos ideales de masculinidad española blanca que se construyen en contraposición con Guinea Ecuatorial y conviven en el siglo XXI: el ideal del explorador heroico heterosexual, que estudio en la primera parte del artículo, y el del aventurero liberal homonormativo, que abordo en la segunda. Mi metodología se fundamenta en el análisis del discurso propio de la historia sociocultural e incorpora una perspectiva postcolonial. Me pregunto cómo se conjugan el género y la nación en los discursos contemporáneos españoles sobre Guinea Ecuatorial². ¿Qué masculinidades pujan por ocupar un espacio hegemónico identificado con la nación española? ¿Cómo se articulan dichas masculinidades? ¿Qué feminidades y masculinidades excluyen? ¿Cómo las tensiones entre diversas formas de entender la masculinidad moldean el debate sobre la modernidad española? ¿Qué relatos sobre la modernidad promueven esas masculinidades? Y ¿cómo se relacionan con el neoliberalismo y con el orden postcolonial? Utilizo para el análisis principalmente, aunque no únicamente, fuentes literarias publicadas en las dos primeras décadas del siglo XXI en las cuales las identidades españolas masculinas postimperiales ocupan un lugar central.

3. Entiendo el género, siguiendo a Joan W. Scott, como un discurso atravesado por relaciones de poder que es construido históricamente a través de prácticas discursivas y, por tanto, como una categoría útil para el análisis histórico de los procesos que han definido roles de género. Véase: ScotT W., Joan: Género e historia, México, Fondo de Cultura Económica, 2008. Sobre la relación entre género y nación, véase el trabajo clásico de Nira Yuval-Davis: Gender and Nation, Londres, Thousand Oaks (California), Nueva Delhi: Sage, 1997. 


\section{Nostalgias coloniales. El arQuetipo Del EXPlORAdOR}

La modernidad española está siendo permanentemente cuestionada. En ese proceso, diversos autores rememoran el pasado colonial para articular un relato sobre el papel civilizador de España en tierras africanas. La nación es simbolizada en clave de género por el arquetipo de un hombre blanco heterosexual que emula a los exploradores que sembraron el imperialismo europeo en África. Estos hombres soñadores, deseosos de tener nuevas experiencias y de alcanzar el reconocimiento y la gloria de sus iguales, ampliaron los límites de las tierras conocidas por los europeos y participaron así en la formación de las naciones europeas modernas. Se trata de una masculinidad encarnada en cuerpos fuertes, atléticos, musculados, que a día de hoy visten sombreros de explorador y portan mapas, armas, cuchillos, pistolas, que les han de permitir la supervivencia, sin descartar el ejercicio de la violencia en una naturaleza hostil ${ }^{4}$.

Este tipo de masculinidad, caracterizada por la erotización del estoicismo, la toma de riesgos y la dominación de las personas más débiles alcanza su versión más violenta en el militarismo, que conecta con las trayectorias de las masculinidades coloniales 5 . En este sentido, Joane Nagel se ha referido a la conexión estrecha entre nacionalismo, patriotismo, militarismo, imperialismo y masculinidad y a cómo los hombres que se sitúan y producen este tipo de masculinidad están defendiendo una concepción particular de género, sexual y racial de sí mismos, construyéndose como hombres blancos heterosexuales ${ }^{6}$. En la representación del imperio español, este modelo de masculinidad ha sido el hegemónico.

La identidad nacional española se ha construido desde sus inicios como una nación colonial e imperial. Como reacción a la pérdida de las colonias en el Caribe y el Pacífico, en 1898, se produjo una crisis de masculinidad nacional ${ }^{7}$. A su vez, las guerras de Marruecos actuaron como un elemento de construcción nacional a través de una masculinidad imperial. El proyecto de conquista era también un proyecto civilizador en el que la virilidad colonial/imperial se comprendía como moderna y civilizada. Por su parte, la Guinea Española fue considerada una fuente de prestigio nacional ${ }^{8}$. En la

4. Véase, como ejemplo de este modelo de masculinidad, el reportaje publicado en 2019 por el diario El País y las imágenes que lo acompañan: Ayala UGARTE, Álex: «Miguel Gutiérrez Garitano, funcionario durante el año y explorador en vacaciones”, El País Semanal, 29 de septiembre de 2019.

5. Higate, Paul y John Hoton: "War, Militarism and Masculinities», en Kimmel, Michael, Jeff Hearn y Raewyn Connell (eds.): Handbook of Studies on Men and Masculinities, Londres, Thousand Oaks (California) y Nueva Delhi, Sage Publications, 2005, pp. 432-447 (pp. 434-435).

6. Nagel, Joane: "Nation» en en Kimmel, Michael, Jeff Hearn y Raewyn Connell (eds.): Handbook of Studies on Men and Masculinities, op. cit., pp. 397-414 (p. 258).

7. Aresti, Nerea: "A la nación por la masculinidad. Una mirada de género a la crisis del 98" en Mary Nash (coord.) Feminidades y masculinidades: arquetipos y prácticas de género, 2014, pp. 47-74.

8. Véanse: Torres Delgado, Gemma: «La reivindicación de la nación civilizada: masculinidad española en el discurso colonial sobre Marruecos (1900-1927)». Cuadernos de Historia Contemporánea, n 39, 2017 , 
España postimperial de principios del siglo XX, género y nación se entrelazan tanto en el relato de las conquistas pasadas, como en el de las aventuras recientes. Diversas obras contemporáneas ambientadas en la antigua colonia española moldean un discurso sobre la nación española articulado en clave de una masculinidad moderna y civilizadora.

En 2010 Miguel Gutiérrez Garitano publicó su obra La aventura del Muni, que fue editada por Ikusager, una editorial vasca modesta. Al año siguiente de su publicación, el libro recibió el Premio Internacional de Literatura de Viajes Camino del Cid, uno de los más importantes en Europa en esta temática. El jurado del premio estaba presidido por la prestigiosa periodista Rosa María Calaf. El premio, dotado de trece mil euros, fue financiado por el Consorcio del Camino del Cid, una entidad pública conformada por las Diputaciones Provinciales de Burgos, Soria, Guadalajara, Zaragoza, Teruel, Castellón, Valencia y Alicante. Tras recibir el galardón la editorial publicó una segunda edición.

La aventura del Muni narra las vivencias del autor en dos viajes realizados a Guinea Ecuatorial, entre 2002 y 2005, de dos meses de duración total. Dichas vivencias se mezclan con la narración de episodios de la historia y la cultura de Guinea y con pasajes sobre el explorador vasco Manuel Iradier y Bulfy, que a finales del siglo XIX realizó dos exploraciones en la costa oriental africana, en el golfo de Guinea. No en vano, el título original del libro incorporaba el subtítulo: "Tras las huellas de Iradier. La historia blanca de Guinea Ecuatorial», que fue eliminado posteriormente. Gutiérrez Garitano siente por Manuel Iradier y por otros exploradores europeos, como Henry Morton Stanley, David Livingstone o Richard Burton, una fascinación que tiene su origen en su niñez, cuando la lectura de libros sobre sus viajes despertó en él la curiosidad por África. Con este libro el autor rinde homenaje a Manuel Iradier, vitoriano y español, como él, y trata de emular sus vivencias africanas más de un siglo después.

Garitano se muestra en el relato como una encarnación de aquellos hombres valientes, sin miedo a morir en tierras lejanas, ansiosos por recorrer territorios nunca antes pisados por los europeos, guiados por fieles hombres nativos. Se identifica especialmente con Iradier sobre quien publicó posteriormente una biografía Apuntes de la Guinea. Vida, obra y memoria de Manuel Iradier y Bulfi (2011). Este autor escribió los textos que acompañaron a la exposición Manuel Iradier. Cien años de un mito, que fue exhibida en Vitoria en 2011 con motivo de la conmemoración de la muerte del explorador?. La exaltación de este personaje, conlleva asimismo la de la nación en nombre

pp. 59-81 y "La nación viril. Imágenes masculinas de España en el africanismo reaccionario después de la derrota de Annual (1921-1927)", Ayer, n 106, pp. 133-158; Álvarez Chillida, Gonzalo y Eloy Martín Corrales: "Haciendo patria en África. España en Marruecos y en el Golfo de Guinea», en Javier MorEno LuZÓN y Xosé Manuel NúÑ̃z SEIXAS (eds): Ser españoles. Imaginarios nacionalistas en el siglo XX, Barcelona, RBA, 2013, pp. 399-432 (p. 428).

9. La exposición tuvo lugar en la Sala Fundación Caja Vital Kutxa y fue comisariada por Fernando Martínez Viñaspre. Además de un homenaje a Iradier, la exposición daba cuenta de la Vitoria ilustrada que albergó en el siglo XIX el segundo ateneo científico de España. Véase: GónGORA, Francisco: «Vitoria descubre 
de la cual se llevaron a cabo aquellas hazañas, España, que debe estar orgullosa de las conquistas y descubrimientos de Iradier, realizados con escasísimos recursos económicos, en comparación con los medios de que dispusieron otros exploradores europeos.

Miguel Gutiérrez Garitano se identifica con aquellos hombres europeos conquistadores y con otros que, como él, encarnan a los exploradores del siglo XXI, como Mario, un médico a quien conoce en Guinea Ecuatorial:

En Cogo conocí, en el seno de mi primer viaje a Guinea, a Mario, un médico procedente del pirineo aragonés, de Vilanúa, que había residido en el país desde finales de los setenta hasta comienzos del presente siglo. Con su gallarda apostura de conquistador español de la época de Pizarro o Cortés, más que un galeno, Mario es un aventurero a la antigua usanza, como Miguel de la Quadra Salcedo o César Pérez de Tudela. Ha recorrido África desde el Sahara hasta el Congo, incluyendo una estancia en Rwanda en plena época del genocidio hutu, que casi le cuesta la vida. En Guinea es una verdadera celebridad y lo conocen hasta en el último pueblo, aun en el lugar más recóndito de la selva. Sus hazañas - como la de cruzar a nado el estuario del Muni en dos ocasiones o remontar los ríos en su kayak de fibra de vidrio o perderse en el bosque en numerosas excursiones - son, todavía hoy, muy comentadas (...) Compartíamos, pienso, una visión del mundo parecida, en la que los sucesos eran cribados en función de su contenido épico ${ }^{10}$.

En esa misma línea, Juan Luis Oliva de Suelves muestra una admiración similar a la de Garitano por la figura de Manuel Iradier, que es exaltada como símbolo del valor de la nación española:

Manuel Iradier, nacido en Vitoria en 1854, es el más grande explorador español del siglo XIX, comparable en todos los aspectos a los más célebres y esclarecidos exploradores ingleses y franceses, de fama internacional. Su vida parece extraída de las novelas de aventuras de autores como H. R. Haggard, Julio Verne o Emilio Salgari. Sus dos viajes de exploración al África Ecuatorial, los más importantes realizados por un español al África Subsahariana, redundaron no sólo en la consecución de un inestimable estudio geográfico, biológico, etnológico y lingüístico, sino también en la gestación política de nuestra ex colonia ${ }^{11}$.

En relación con este modelo de masculinidad, resulta llamativa la fascinación que provoca el culto del bwiti o mbwiti en los hombres blancos españoles que visitan Guinea. El bwiti es una religión sincrética, basada en el culto a los antepasados, que mezcla elementos cristianos y animistas. Este culto estuvo prohibido durante la colonia, por lo que se ha visto rodeado de un aura de misterio y en ocasiones ha sido vinculado

a Manuel Iradier», El Correo, 9 de septiembre de 2011, pp. 46 y 47. Este homenaje, al igual que el que lleva a cabo Miguel Gutiérrez Garitano en La aventura del Muni, se enmarca dentro de un discurso que identifica el ámbito local, Vitoria, con la nación española.

10. Gutiérrez Garitano: Miguel: La aventura del Muni, Vitoria-Gasteiz, Ikusager, 2011, pp. 150-151.

11. Oliva de Suelves, Juan Luis: Luna llena en Medouné, Barcelona y Buenos Aires, Edhasa, 2008, p. 32. 
con las supuestas prácticas antropofágicas de los africanos. Esa prohibición colonial fomentó el interés de muchos viajeros españoles por los ritos realizados en secreto por los practicantes de este culto en el interior de la selva. Contemplar e incluso tomar parte en uno de esos ritos constituye para muchos viajeros españoles blancos una obsesión. Este es el caso de Miguel Gutiérrez Garitano, quien narra en su libro cómo en su segundo viaje a Guinea se inició en este culto y los riesgos que superó tras participar en un ritual que pudo haberle costado la vida. Dicho rito conlleva la ingesta de iboga, un arbusto que crece en el África ecuatorial y cuya raíz tiene propiedades estimulantes y, en grandes cantidades, alucinógenas. La participación de Garitano en aquellas ceremonias, acompañado de una comunidad de ecuatoguineanos que celebran su entrada en la comunidad con bailes africanos, simboliza el descubrimiento por parte del hombre blanco de los misterios del continente africano. Asimismo, reafirma la masculinidad del hombre blanco cuyo cuerpo es capaz de superar los retos y peligros de la naturaleza.

$\mathrm{Al}$ igual que Gutiérrez Garitano, el cazador y escritor Juan Oliva de Suelves pretende desvelar los secretos de África. En su obra, Luna llena en Medouné (2008), narra los viajes realizados a Guinea Ecuatorial en 1966 y en 1969 con el objetivo de participar en safaris de caza. Esta obra da cuenta de la fascinación por el rito del bwiti que profesa su autor, así como de su nostalgia de la época colonial en la que "casi todo lo que los españoles hicieron en Guinea funcionaba bien» ${ }^{12}$. Además del bwiti, aparece en la narración la supuesta antropofagia de los africanos y su gusto por la carne de mono, prácticamente tabú para los europeos, quizás por la influencia de las teorías darwinistas. El misterio que rodea al bwiti permite presentar a los africanos como «Otros» exóticos, atrapados en el tiempo y necesitados de tutela para poder avanzar hacia un estadio superior de civilización.

Si en el pasado los territorios del Muni debieron suponer para Iradier un canto de sirena, aquella peligrosa belleza se ha convertido hoy en un país que a ojos de autores como Gutiérrez Garitano está corroído por la miseria moral, el desastre y la corrupción. Guinea Ecuatorial se muestra para este más atractiva por su pasado colonial —idealizado por los españoles- que, por su presente, en el que éstos no son, según Garitano, bien recibidos. Este autor considera que los guineanos habrían de estar agradecidos a los españoles por la contribución contemporánea del Estado español al desarrollo del país a través de la ayuda humanitaria, cuyo objetivo es, supuestamente, modernizarlo. Guinea Ecuatorial es uno de los principales receptores del presupuesto español de Cooperación Española. Entre 2005 y 2012 la Ayuda Oficial al Desarrollo (AOD) fue de más de cien millones de euros ${ }^{13}$.

12. Oliva de Suelves, Juan Luis: Luna llena en Medouné, op. cit., p. 19.

13. Sin embargo, no puede desligarse dicha política exterior de las relaciones económicas entre España y su antigua colonia. Empresas españolas tienen intereses en el país y Guinea Ecuatorial suministra hidrocarburos a España. Véase el documento elaborado por la Oficina de Información Diplomática: "Guinea Ecuatorial. Ficha país», Ministerio de Asuntos Exteriores, Unión Europea y Cooperación, 8 páginas. www. 
Guinea es un país, por otra parte, particularmente antipático para los españoles. Como otros regímenes totalitarios africanos, el de Malabo — capital de Guinea- utiliza la retórica anticolonialista como un elemento más para sostener su política. Y así, mientras España gasta cada año más de siete millones de euros en ayuda sanitaria y escolar para Guinea, Malabo responde haciendo cada día más incómoda su presencia a los españoles que residen en el país o lo visitan ${ }^{14}$.

Gutiérrez Garitano preside hoy la Asociación Africanista Manuel Iradier, dedicada a la cooperación para el desarrollo en África. De hecho, el autor viajó oficialmente a Guinea para supervisar los proyectos de cooperación coordinados por esta asociación. La Asociación Africanista tiene varios proyectos educativos y sanitarios en Cogo, ciudad situada en el estuario del río Muni. La que fuera conocida durante la época colonial como Puerto Iradier es el centro de operaciones de los viajes de Garitano. El relato del autor participa de una teoría del desarrollo que ha recibido fuertes críticas. Desde una perspectiva decolonial, la teoría del desarrollo es considerada como un marco interpretativo colonial. Surgida en el contexto posterior a la Segunda Guerra Mundial, en Estados Unidos y Europa, y aceptada por las élites de otros países, pretende transformar las culturas y formaciones sociales de Asia, África y América Latina según los parámetros del autodenominado Primer Mundo, supuestamente desarrollado. Esta teoría conlleva la creación de una categoría (el Tercer Mundo) que identifica a aquellos países que se encuentran más alejados de los parámetros sociales y económicos europeos. En esta línea, Arturo Escobar ha señalado cómo el discurso desarrollista dio lugar a un régimen de representación que «inventó» el Tercer Mundo. Este sistema jerarquizado está atravesado por relaciones de poder que subyugan a los países identificados como parte del Tercer Mundo y tienden a eliminar las prácticas sociales e imaginarios culturales de otros espacios colonizados, situándolos bajo el umbral del subdesarrollo. Esta interpretación constituye una teoría de la modernización y adquiere sentido en el marco de una historia lineal en la que el denominado Primer Mundo se concibe a sí mismo como modelo a seguir. La teoría del desarrollo conlleva, por tanto, una epistemología atravesada por una lógica de dominación colonial ${ }^{15}$.

exteriores.gob.es, consultado el 11 de abril de 2020. Un análisis crítico sobre las relaciones políticas y económicas entre España y Guinea Ecuatorial en: Campos Serrano, Alicia y Jordi SANT Gisbert, "Petróleo y estado postcolonial: transformaciones de la economía política en Guinea Ecuatorial, 1995-2010. Implicaciones para la coherencia de políticas españolas», Avances de Investigación, n 54, 2011, pp. 2-151. Sobre las imbricaciones entre las compañías petrolíferas estadounidenses y la vida de los ecuatoguineanos véase: Appel, Hanna C., "Walls and white elephants: Oil extraction, responsibility, and infrastructural violence in Equatorial Guinea", Ethnography, n' 13, vol. 4, 2012, pp. 439-465.

14. Gutiérrez Garitano, Miguel: La aventura del Muni, op. cit., p. 8.

15. Escobar, Arturo: La invención del Tercer Mundo Construcción y deconstrucción del desarrollo. Caracas: Fundación Editorial el perro y la rana, 2007; Ornellas Delgado, Jaime: «La construcción del desarrollo como categoría colonial». Paradigma económico, n 2, 2010, pp. 58-77. 
Guinea ha padecido dos dictaduras, la de Francisco Macías Nguema entre 1968 y 1979 y la de Tedoro Obiang Nguema que gobierna el país desde 1979. El período dictatorial postcolonial es contrastado en este discurso con una época colonial que, si bien no siempre es idealizada, es considerada como más fructuosa que el período postcolonial ${ }^{16}$. Miguel Gutiérrez Garitano considera, además, que los ecuatoguineanos, como tantos otros africanos (supuestamente salvajes e irracionales) no son capaces de organizarse en regímenes democráticos, y necesitan de una mano de hierro que los gobierne ${ }^{17}$.

Esta perspectiva desarrollista va de la mano de una actitud paternalista que infantiliza a los africanos. En la obra de Oliva de Suelves, los ecuatoguineanos son descritos mediante estereotipos que los presentan como hombres perezosos y fiesteros, si bien justifica su vagancia por la dificultad de realizar trabajos forzados en aquel clima, tareas que los blancos tenían prohibido realizar. No obstante, estos son a menudo representados como ignorantes y despreocupados. Este discurso conecta la supuesta superioridad del hombre blanco europeo con su cultura y con la confianza en la razón por encima de la magia y la hechicería. De este modo, el hombre blanco adopta el papel de maestro con respecto a los pobres ignorantes guineanos. Así Gutiérrez Garitano, tras su encuentro con un chico gabonés, reflexiona en su ensayo sobre los imaginarios que los europeos tienen de África así como sobre las ideas que los africanos poseen,

16. La visión idealizada de la colonia ha sido refutada por numerosos historiadores, antropólogos y escritores. Véanse, entre otros muchos: NDOngo-Bidyogo, Donato: Historia y tragedia de Guinea Ecuatorial, Barcelona, Bellaterra, 2020 [1977]; STUCKI, Andreas: Violence and gender in Africa's Iberian colonies: feminizing the Portuguese and Spanish empire, 1950s-1970s, Cham, Palgrave Macmillan, 2019; Okenve, Enrique: "Colonización, resistencia y transformación histórica fang en Guinea Ecuatorial (1900-1948)", Ayer, 2018, $n^{\circ}$ 109, pp. 109-135; Aixelà-CABré, Yolanda: «Exploring Euro-African pasts through an analysis of Spanish colonial practices in Africa (Morocco and Spanish Guinea)", Canadian Journal of African Studies / Revue canadienne des études africaines, 2017, no 51, vol. 1, pp. 23-42; OBIANG Biko, Adolfo: Guinea Ecuatorial: del colonialismo español al descubrimiento del petróleo, Madrid, Sial, 2016; Nerín, Gustau: Un guardia civil en la selva, Madrid, Ariel, 2008; SundiaTA, Ibrahim H.: Equatorial Guinea: colonialism, state terror, and the search for stability, Boulder, Westview Press, 1990; Ávila Laurel, Juan Tomás: La carga, Valencia, Palmart, 1999; Ndongo-Bidyogo, Donato: Las tinieblas de tu memoria negra, Madrid, Fundamentos, 1987.

17. Guinea Ecuatorial, simbolizada por su capital, Malabo, es feminizada en el relato de Garitano, que se refiere a ella como una mujer que fue bella — en la época de la colonia — pero que ahora se encuentra marchita: "Quizás por ello Malabo me pareció una urbe artificial, cogida con pinzas, que hedía a odio interracial, derrota y aspiraciones incumplidas. Bajo el maquillaje propiciado por la venta de petróleo se adivinaba el rostro demacrado de una dama, en otro tiempo bella, que aspiró a metas elevadas y tropezó siempre con la desidia, la codicia y la maldad de los hombres. Sus más de 60.000 habitantes constituían una comunidad heterogénea y mal avenida, cuya convivencia pacífica sólo parecía poder darse en el seno de un régimen autoritario, como el que detentaba el país en el momento de mi visita y como también lo habia tenido en la época de la colonia española.» GuTIÉrRez GARITANo, Miguel: La aventura del Muni, op. cit. p. 32. Las cursivas son mías. 
según él, de Europa. Dicha reflexión participa de un discurso paternalista, articulado en clave racial ${ }^{18}$.

—¿Dónde está Europa? ¿Tiene costa? ¿Qué es más grande Europa o París? ¿Qué es París? ¿Qué es España? ¿Pertenece a Francia? - y un sinfín de cuestiones más que denotaban su increíble ignorancia.

Mientras ayudado de un palo trataba — dibujando sobre la arena- de iluminar un poco las carencias de aquel chaval, me reafirmé en una creencia que aún mantengo, la de que, mientras África fascina a muchos europeos por considerarla una exótica caja de misterios y aventuras, Europa maravilla a la práctica totalidad de los subsaharianos, que la ven como una tierra de Jauja de difícil acceso. Su obsesión es más comprensible que la nuestra. Ellos sueñan con el viejo continente por sus ventajas tangibles; nosotros, alejados del fantasma del hambre, erigimos en gigante de nuestra imaginación al devastado continente negro ${ }^{19}$.

La sanidad y la educación son los principales elementos que sirven para medir el progreso en el marco interpretativo del desarrollo. Rosa Medina-Domenech ha explicado cómo las prácticas biopolíticas coloniales, que incluían la educación, la sanidad y la burocracia institucional, tenían como objetivo controlar a la población guineana y que esta abandonara sus modos de vida y se españolizara ${ }^{20}$. La teoría del desarrollo conlleva el abandono de tradiciones propias para abrazar la cultura occidental en la creencia de que solo el capitalismo puede modernizar a los pueblos.

De modo similar a como lo hace Gutiérrez Garitano, Oliva de Suelves intercala el relato de sus viajes con explicaciones sobre los pueblos de Guinea Ecuatorial. En ellas el autor clasifica a la población africana según su etnia e identifica a los pigmeos como a los grandes conocedores de la selva, pero también como a los africanos más atrasados, situados en un estadio de desarrollo equivalente al del Paleolítico. Según Oliva de Suelves, los fang, sin embargo, más influidos por los occidentales, tenían mayor educación gracias a la colonización, pero no estaban suficientemente desarrollados económicamente. El autor considera que la colonización española fue muy positiva para los ecuatoguineanos y que favoreció su situación social y económica. Estas reflexiones son un ejemplo de cómo perviven ciertas visiones antropológicas que contribuyeron a crear una epistemología colonial, que sirvió para legitimar la colonización. Este tipo

18. Este discurso racial ha sido contestado por autores como: ZAMORA, Francisco: Cómo ser negro y no morir en Aravaca, Barcelona, Ediciones B, 1994; о Мвомі́о, Lucía: Las que se atrevieron, Madrid, Sial/ Casa de África, 2017.

19. Gutiérrez Garitano, Miguel: La aventura del muni, op. cit., p. 130.

20. Medina Doménech, Rosa: «Sicentific Technologies of National Identity as Colonial Legacies: Extracting the Spanish Nation from Equatorial Guinea", Social Studies of Sciences, 2009, n 39.1, pp. 81-112. Véase también: SAMPEDro VizcaYa, Benita: "La economía política de la sanidad colonial en Guinea Ecuatorial», Endoxa, 2019, no 37, pp. 279-298. 
de relatos sitúan a los investigadores y exploradores blancos en una posición de superioridad frente a los pueblos que son objeto de su estudio ${ }^{21}$.

Desde esta lógica, los ecuatoguineanos, sumidos en el subdesarrollo, habrían de estar agradecidos a los ciudadanos españoles cuyo país invierte fondos y aporta recursos humanos para sacar al país de la pobreza. Garitano denuncia, por ello, la actitud con la que son recibidos los extranjeros blancos en el país y esto le conduce a identificarse, incluso, con la violencia colonial y el militarismo:

Quizás sea lo que más deploro de Guinea Ecuatorial; todo el que ha viajado por esta tierra encuentra Guinea especialmente antipática y exasperante, aun en comparación con países en teoría más peligrosos. Es una tierra en donde el extranjero tiene la extraña sensación de estar siempre cabreado. Si uno no se comporta como un capataz de los de látigo y grillete o como un sargento chusquero, se te ríen con toda desvergüenza en las barbas ${ }^{22}$.

A la elaboración de ese mismo discurso ha contribuido el prolífico escritor y viajero Javier Reverte, autor del prólogo de La aventura del Muni. Desde una perspectiva colonial, atravesada por la teoría del desarrollo, e impregnada de paternalismo, Reverte denuncia la falta de agradecimiento que los ecuatoguineanos muestran a los españoles en la misma línea de Garitano.

Cumplí la asignatura pendiente de visitar un lugar pequeño de mi más amado continente y creo que no debí de haberlo hecho. Una vez tras otra me preguntaba qué hacemos allí los españoles, empleando siete millones de euros anuales en ayuda escolar y sanitaria a Guinea. Pero quedan en mis oídos las palabras de un médico español que trabaja en un hospital del país: "Estás dispuesto a irte todos los días ante el desdén y la humillación a que te someten las autoridades y ante la indiferencia con que te mira mucha gente y los intentos constantes por estafarte. Pero un día escuchas llorar a un niño, sabes que nadie va a hacer nada por él, sabes que a pocos les importa que se muera o no..., ¿y qué haces? Te quedas»²3.

La nostalgia por el pasado colonial se muestra en el ensayo de Garitano no solo cuando se refiere a la ciudad de Malabo, situada en la isla de Bioko, antigua Fernando Poo, sino también cuando camina por las ruinas de Cabo San Juan, en la parte continental del país. En el marco de la teoría del desarrollo, el pasado colonial es interpretado como una oportunidad truncada.

21. Oliva De Suelves, Juan: Luna llena en Medouné, op. cit., pp. 63 y 65. Una reflexión crítica sobre el papel de la antropología en las relaciones coloniales y postcoloniales puede encontrarse en FABIAN, Johannes, Time and the Other. How Anthropology makes its object, Nueva York, Columbia University Press, 2014.

22. Gutiérrez Garitano, Miguel: La aventura del Muni, op. cit., p. 176. El énfasis es nuestro.

23. Reverte, Javier: "Guinea”, El Periódico, 6 de julio de 2007. Desde una perspectiva opuesta a la de Javier Reverte, Gustau Nerín ha criticado fuertemente las prácticas llevadas a cabo por los cooperantes en Guinea Ecuatorial. Véase: Nerín, Gustau: Blanco bueno busca negro pobre. Una crítica de los organismos de cooperación y las ONG, Barcelona, Roca Editorial de Libros, 2011. 
Explorador contemporáneo, Garitano padece lo que otros exploradores, como Manuel Hernández Sanjuán, llamaron "el mal de África», una especie de deseo irrefrenable por un continente que pone a prueba las capacidades físicas de los hombres blancos heterosexuales. África es comprendida en este relato como un territorio salvaje, dominado por una violencia atávica que solo ciertos hombres pueden domeñar. Esta forma de imaginar África como una mujer peligrosa por la que el explorador siente un deseo irrefrenable de conquista pone de manifiesto una mirada orientalista que ha sido estudiada en profundidad ${ }^{24}$. Desde una perspectiva orientalista, Garitano imagina a África como a una femme fatale, objeto del deseo de los imperialistas y también origen de sus miedos:

Como una llaga sobre el ombligo del que Stanley apodara el país de los bosques, la cuenca del Muni era un escenario salvaje e incierto, al más puro estilo del África de la época victoriana. Guerreros antropófagos, exploradores, piratas, traficantes de esclavos han cruzado sus lúgubres aguas. Muchas fueron las veces en que sus fondos fangosos se regaron con la sangre de hombres, que durante siglos han evitado este universo inclemente, este escenario inmemorial, bello y terrible como una femme fatale $^{25}$.

El África salvaje que fascinó a Iradier es articulada en clave sexual, pero Garitano se muestra muy disgustado por la actitud que numerosas mujeres guineanas muestran hacia él y hacia otros hombres blancos con quienes pretenden mantener relaciones sexuales. La mujer guineana aparece así como una buscona, acosadora de hombres blancos. Oliva de Suelves se pronuncia asimismo sobre las mujeres ecuatoguineanas, que le parecen más disciplinadas y trabajadoras que los hombres, debido a su sometimiento y al maltrato que reciben de ellos. El lugar que ocupan las mujeres en el proceso de emancipación —entendido siempre desde una perspectiva occidental — se utiliza como prueba del retraso de los pueblos ecuatoguineanos:

Las mujeres en estado de gravidez incipiente también curraban, algunas de ellas eran bellas jovencitas de doce o trece años, precisamente las más apetecibles para los mandamases de los poblados. Estas muchachas adolescentes muestran unos senos bellos y enhiestos y sus dulces y poco remarcadas caras aniñadas presentan aspectos más cercanos a los semblantes de las jóvenes de raza indoeuropea. Pero, pronto, desgraciadamente muy pronto, debido a la frecuente maternidad y a los trabajos que tan duros resultan para su sexo, parecerán todas ellas más viejas. La mujer florece muy pronto en este trópico suave y caliente y consume y quema también muy pronto toda su belleza y su enorme sensualidad ${ }^{26}$.

24. Véanse, por ejemplo: SAID, Edward W.: Orientalismo, Barcelona: Debolsillo, 2003; McCunTOck, Anne: Imperial leather: race, gender and sexuality in the colonial, Neva York: Routledge, 1995; YEĞENOĞLU, Meyda: Colonial fantasies. Towards a feminist reading of Orientalism, Cambridge: Cambridge University Press, 1999.

25. Gutiérrez Garitano, Miguel: La aventura del Muni, op. cit., p. 18.

26. Oliva de Suelves, Juan Luis: Luna llena en Medouné, op. cit., pp. 122-123. El énfasis es nuestro. 
El grado de emancipación de la mujer se torna de este modo en prueba de la modernidad o atraso de los pueblos. De este mismo discurso modernizador participa la novela de Javier Reverte, La canción de Mbama, que articula un modelo de masculinidad muy similar. Publicada originalmente en 2007 en Círculo de Lectores, con el título Una bistoria africana, fue reeditada en 2011 por Plaza y Janés ${ }^{27}$. El libro está dedicado a la Asociación Africanista Manuel Iradier y narra la historia de un médico navarro, Luis Urzaiz, que dirige un hospital en Guinea y aspira a recibir el Premio Nobel de la Paz. Como Gutiérrez Garitano y Oliva de Suelves, Urzaiz es un trasunto contemporáneo del explorador Manuel Iradier. Llegó a Guinea en tiempos de la colonia y decidió quedarse tras la independencia del país africano, dejando que su mujer y su hijo regresaran a España. Vive en Cogo, antigua Puerto Iradier, con una mujer joven, ndowé, Melita, que se dedica a su cuidado y con quien mantiene relaciones sexuales. Melita ha dejado a su familia para convivir con Urzaiz y mantiene con él una relación de dependencia, arropada por el mito del amor romántico. En la novela de Reverte, el médico vasco se enfrenta con su enemigo, Mbama, un ecuatoguineano que trabaja como policía al servicio del dictador Francisco Macías, y que fue torturado por los españoles. En la persecución de Mbama, Urzaiz se adentra río Muni arriba, en el corazón de la selva, a riesgo de perder la vida. Ambos, Melita y Mbama, constituyen los «Otros» del hombre blanco español. Melita es descrita como buena salvaje, mientras que Mbama, el único personaje que denuncia la violencia del orden colonial representa al salvaje asesino y vengativo, la corrupción que arrasa Guinea tras su independencia de España. Melita representa el África imaginada de los conquistadores europeos; simboliza a Guinea, una Guinea que ama al antiguo colonizador español y satisface sus deseos eróticos. El ideal de masculinidad española heroica y heterosexual que autores como Miguel Gutiérrez Garitano, Juan Luis Oliva de Suelves o Javier Reverte construyen en oposición a la alteridad ecuatoguineana convive con otro modelo de masculinidad (homosexual) que incorpora también una fascinación por el exotismo y la aventura ligados a la antigua colonia española.

\section{2. «UN NUEVO HOMBRE MODERNO»: BLANCO, DE CLASE ALTA Y HOMOSEXUAL}

Las masculinidades son el resultado de prácticas discursivas que se llevan a cabo en contextos sociales concretos. No representan tipos de hombres, sino la manera en que ciertos hombres se posicionan a sí mismos a través de prácticas discursivas. Las sociedades coloniales y los estados nación se establecieron sobre la producción de divisiones y jerarquías de género, de clase y raciales. El orden social imperial dio lugar a una escala de roles de género (y de masculinidades), así como a escalas raciales. Siguiendo

27. ReverTe, Javier: La canción de Mbama, Barcelona: Plaza y Janés, 2011. 
a Raewyn Connell, entiendo por masculinidad hegemónica aquella que representa un ideal socialmente aceptado como dominante, aunque no necesariamente actuado, que engloba una serie de prácticas y formas de ser hombre en un determinado contexto social. Este modelo de masculinidad excluye otros modelos que adquieren respecto a aquél una posición subordinada o marginal y dan lugar a masculinidades despreciables o subalternas. La masculinidad hegemónica se opone no solo a otras masculinidades sino también a modelos de feminidad, subordinados al modelo de masculinidad que es considerado normativo en un cronotopo concreto $^{28}$.

El orden neoliberal que emergió en los años setenta y ochenta dio lugar a numerosos cambios en las sociedades contemporáneas y, por supuesto, estos cambios tuvieron un carácter generizado. El neoliberalismo no solo destruye instituciones y derechos, sino que es también productivo; produce nuevos tipos de relaciones sociales, de identidades, de subjetividades y de formas de vida. La gubernamentalidad neoliberal se fundamenta en la lucha económica, la competición generalizada, el individualismo, la transformación de los individuos para que se conduzcan a sí mismos como empresas, todo ello en nombre de la libertad individual y del derecho a acumular y concentrar propiedad privada $^{29}$. Según Connell, con el colapso del estalinismo y el final de la Guerra Fría, un modelo de masculinidad egocéntrica, calculadora, vinculada al modelo de hombre capitalista y emprendedor ocupó el ideal de masculinidad en el ámbito global.

No obstante, los discursos de género, al igual que los discursos nacionales, se mantienen siempre en un equilibrio inestable. Las masculinidades hegemónicas y las variedades subordinadas de los grupos dominantes se han adaptado a las nuevas circunstancias sin romper el modelo social neoliberal. Las naciones postcoloniales se han apropiado de modelos de masculinidad coloniales, reinterpretándolos, con el objetivo de articular nuevos discursos nacionales ${ }^{30}$. Aquí nos preguntamos: ¿Qué modelos de masculinidad representan hoy en día una nación española próspera y moderna? ¿Quiénes son los adalides del progreso y de la civilización? Sin duda, nos hallamos ante una pugna por definir los parámetros de la modernidad.

Junto al arquetipo del conquistador de África, estudiado en el apartado anterior, conviven hoy otros modelos de masculinidad española que no cuestionan abiertamente

28. Véanse: Conneld, Raewyn: "Globalization, Imperialism and Masculinities», en: Kimmel, Michael, Jeff HeArn y Raewyn Connell (eds.): Handbook of Studies on Men and Masculinities, op. cit., pp. 71-89 y AREsti, Nerea: "La historia de género y el estudio de las masculinidades: reflexiones sobre conceptos y métodos", en Gallego Franco, Henar (ed.): Feminidades y masculinidades en la bistoriografía de género, Granda, Comares, 2018, pp. 173-194.

29. CORNWALl, Andrea: «Introduction: masculinities under neoliberalism» en: CoRnwall, Andrea; Frank G. KARIORIS y Nancy LiNDISFARNE (eds.): Masculinities under neoliberalism, Londres, Zed Book, 2016, pp. 1-28.

30. Connell, Raewyn: "Globalization, Imperialism, and Masculinities», op. cit., pp. 75, 76 y 84. Connell, R. W. y James W. Messerschmidt, "Hegemonic Masculinity. Rethinking the Concept», Gender and Society, vol. 19, no 6, 2005, pp. 829-859. 
el ideal socialmente aceptado (hombre blanco, con recursos económicos y heterosexual), ni el discurso sobre la modernidad española, sino que contribuyen a reforzarlos. Raewyn Connell se ha referido a este tipo de masculinidades como "masculinidades cómplices». Por su parte, Heidi Nast ha estudiado el fenómeno por el cual modelos de masculinidades homosexuales que en el pasado ocuparon una posición marginal han adquirido hoy — dentro del marco neoliberal — una posición privilegiada, y han dado lugar a lo que ella denomina "gay white patriarchies» ${ }^{31}$.

En esta línea, Jasbir Puar ha estudiado cómo las personas homosexuales blancas, en un contexto de reforzamiento de la supremacía blanca y del imperialismo occidental, se han incorporado al neoliberalismo y ocupan, a través del consumo, posiciones de privilegio que antes les estaban vetadas. En este sentido, las ideologías homonormativas refuerzan y acompañan las tradicionales ideologías heteronormativas, reproduciendo ideales similares que mantienen la dominación de determinadas poblaciones sobre otras. Esta dominación se articula en términos de "raza», clase, género y nacionalidad. Este discurso ha sido identificado como homonacionalismo. En algunos países occidentales asistimos a un cambio en los modos en que los sujetos queer se han relacionado con los Estados nacionales, en los que han pasado de ser meras cifras de mortalidad a causa del VIH a ser asociados con ideas de vida, familia, y producción de vida. Las relaciones de convivencia entre los sujetos homosexuales, el nacionalismo, el imperialismo, el neoliberalismo y las tecnologías de la vigilancia han dado lugar a la proliferación y visibilización en el espacio público de sujetos queer liberales, que ocupan nuevos espacios de poder. Sin embargo, como esta autora explica con el foco puesto en el caso estadounidense, las políticas de reconocimiento e incorporación a la nación de ciertos sujetos homosexuales, arropados por discursos liberales, conlleva la segregación de otros sujetos homosexuales racializados. Esta autora denuncia cómo, mientras se incorpora a la nación a los sujetos queer homonormativos, los sujetos queer racializados son señalados para su abandono, supresión o muerte. El reconocimiento y la inclusión de ciertos sujetos queer se supedita de este modo a la segregación y exclusión del imaginario nacional de los «Otros» raciales y sexuales. En este sentido, Puar constata la complicidad de ciertos sujetos homosexuales con formaciones nacionalistas cuyo ideal normativo prioritario es la heterosexualidad. Según esta autora, la homonormatividad habita y reproduce las normas heteronormativas. La homonormatividad sirve así para reafirmar la supuesta modernidad de unas sociedades y la monstruosidad de otras. El matrimonio gay se ha convertido de este modo en un nuevo elemento que señala la diferencia entre civilización y barbarie ${ }^{32}$.

31. NAST, Heidi J.: "Queer Patriarchies, Queer Racisms, International», Antipode, 34.5, 2002, pp. 874-909.

32. Puar, Jasbir K.: Ensamblajes terroristas. El bomonacionalismo en tiempos queer, Barcelona, Ediciones Bellaterra, 2017. 
En relación con esto se encuentra el fenómeno conocido como pinkwhasing, que utiliza la homosexualidad para mostrar a unas sociedades como tolerantes, diversas, modernas y democráticas frente a otras, y sirve para ocultar las complicidades políticas de dichas naciones con prácticas opresivas. Sara Ahmed considera que lo queer, de la mano de una ideología liberal, se propone como elemento cosmopolita y elitista que se sitúa en un terreno supuestamente apolítico y consensuado. Pierde así toda carga política de resistencia a los modelos heteronormativos y supremacistas blancos ${ }^{33}$. La mecánica queer se convierte en cómplice de las violencias normativas de Estado que actúan a través de la biopolítica. La «transgresión» asociada tradicionalmente a lo queer sirve en este caso para la construcción de identidades raciales, de clase, de género y nacionales que refuerzan la hegemonía de la blanquitud ${ }^{34}$. La liberación de los individuos queer asociada en este caso a la nación española, sirve para identificar a otras comunidades, naciones o etnias, como más homófobas que la española y, en consecuencia, como más atrasadas. Esta ideología homonormativa y supremacista ignora las disparidades económicas, los contextos históricos y sociales, y las relaciones de poder coloniales. Naturaliza, por tanto, las diferencias culturales e históricas y despolitiza las luchas de los colectivos LGTBI+.

Raewyn Connell, en sus estudios sobre la masculinidad hegemónica, identificó una masculinidad cosmopolita vinculada con el hombre de negocios que opera en un ámbito transnacional. El caso de estudio que abordo a continuación tensiona dicha masculinidad y está relacionado con ella. Luis Melgar Valero es diplomático y funcionario del Ministerio de Asuntos Exteriores de España. Trabajó como subdirector de Diplomacia Pública bajo las órdenes del ministro José Manuel García-Margallo, durante el gobierno de Mariano Rajoy. Entre agosto de 2013 y julio de 2016 ocupó la segunda jefatura de misión de la embajada de España en Guinea Ecuatorial, situada en Malabo. Posteriormente fue destinado a la embajada de Venezuela y actualmente es primer secretario de la Embajada de España en China. En 2017, tras su estancia en Guinea, publicó su libro Los blancos estáis locos. Un diplomático español en Guinea Ecuatorial, editado por Planeta y basado en las experiencias vividas durante su estancia en Guinea. En 2013, según cuenta el propio escritor, poco antes de su viaje al país ecuatorial, él y su marido, Pablo Martín Ávila, fueron portada en la revista semanal del diario conservador El Mundo, tras haberse casado en presencia del entonces ministro de asuntos exteriores, García-Margallo. Luis Melgar portaba para la ocasión el uniforme de gala del cuerpo diplomático español, que tiene su origen en el siglo XIX. Solo algunas monarquías utilizan hoy en día este tipo de uniforme. Luis Melgar presentó su libro en Madrid en 2017, en la Escuela Diplomática del Ministerio de Asuntos Exteriores y Cooperación,

33. Ahmed, Sarah: The Cultural Politics of Emotion, Edimburgo: Edinburg University Press, 2014, pp.151-152, y PUAR, Jasbir K: Ensamblajes terroristas, op. cit., p. 67.

34. PUAR, Jasbir K: Ensamblajes terroristas, op. cit., p. 69. 
en compañía de Purificación Angue Ondo, embajadora de la República de Guinea Ecuatorial en España y del ministro José Manuel García-Margallo.

Los blancos estáis locos tiene su origen en los textos breves que Luis Melgar compartía con familiares y amigos sobre sus vivencias en Guinea y que estos recibían asiduamente bajo el título «Perlas de África». En el libro narra las peripecias acontecidas en compañía de familiares y amigos durante el tiempo en que estuvo destinado en la embajada española en Guinea Ecuatorial. Si bien el protagonista es el propio Luis Melgar, su particular álter ego es Yolanda, una mujer guineana que trabaja en el servicio de la casa de los Melgar, situada dentro del complejo residencial de la embajada. Es ella quien da título al libro, con una exclamación que apela a la falta de cordura de los blancos, cuando se entera de que sus nuevos jefes son una pareja de hombres y que están casados. Yolanda es la principal conexión del matrimonio con el mundo subalterno de Guinea Ecuatorial, y su forma de mirar y comprender a la pareja y su mundo constituye el hilo conductor del relato. Escrito con un estilo fresco Los blancos estáis locos naturaliza las diferencias socioeconómicas y despolitiza ciertas prácticas sociales. Si bien el pasado colonial resulta ineludible, la reflexión sobre las consecuencias de la colonización brillan en el texto por su ausencia. Los ecuatoguineanos quedan vinculados de un modo amable con la magia, la irracionalidad, el surrealismo, la naturaleza salvaje (comen de todo, como los animales) o la tortura, de la que hablan a menudo con frivolidad, como mecanismo necesario para enderezar a ciertos individuos descarriados. Destacan así episodios narrados en clave de humor y desconectados del pasado de la colonia. Un tema recurrente es también aquí el éxito que los hombres europeos blancos tienen en Guinea con las mujeres guineanas.

Autoras como María Lugones, Oyèrónkẹ Oyěwùmí o Paula Gunn Allen han estudiado cómo las categorías de género y raza están indisolublemente unidas y cómo el sistema de género entendido de manera binaria fue impuesto a otras sociedades tras la colonización, junto con determinadas divisiones del trabajo jerarquizadas y racializadas ${ }^{35}$. Resulta en buena medida irónico que en la actualidad se utilice la emancipación de las personas LGTBI como elemento para medir el grado de modernidad de los pueblos del sur global.

Del mismo modo que la modernidad de la nación se sostiene sobre la homonormatividad de la blanquitud, la llamada «excepcionalidad de género» es utilizada como mecanismo de subordinación de unas naciones y comunidades respecto a otras. El relato sobre la excepcionalidad de género propone rescatar a las «mujeres del tercer

35. Lugones, María: "Colonialidad y Género» en Cairo, Heriberto y Ramón Grosfoguel (eds.): Descolonizar la Modernidad, Descolonizar Europa: Un diálogo Europa-América Latina, Madrid: Iepala, 2010, pp. 57-84; OYĚWùmí, Oyèrónkẹ: The invention of women: making an African sense of Western gender discourses, Minneapolis, University of Minnesota Press, 1997; Gunn AlLEn, Paula: The sacred hoop: recovering the feminine in American Indian traditions, Boston, Beacon Press, 1992 [1986]. 
mundo» de sus homólogos masculinos, calificados como violentos y salvajes ${ }^{36}$. Chandra Talpade Mohanty explicó ya a mediados de los años ochenta cómo la categoría de "mujer del tercer mundo» era articulada por numerosas feministas occidentales, quienes se consideraban a sí mismas como mujeres modernas cultas y liberadas sexualmente, por oposición a las mujeres de los países no occidentales, presentadas como incultas, atrasadas y oprimidas ${ }^{37}$. Joan Scott, por su parte, ha estudiado cómo en la segunda mitad del siglo XX el cristianismo se vinculó con el secularismo a través de la emancipación sexual, que pasó a ser considerada como un indicador fundamental de la igualdad de género y la modernidad de una sociedad. En la Segunda Guerra Mundial la libertad fue definida como agencia sexual y como emblema de la superioridad de la civilización occidental. Según este argumento, el apoyo de una sociedad a la libertad sexual señala su compromiso con los principios de tolerancia e igualitarismo. La libertad sexual de las mujeres y la aceptación social de la homosexualidad se convierten de este modo en signos de modernización. Según esta autora, «[t]he focus on liberated sexuality (whether hetero or homosexual) echoes with the notion of consumer desire as the motor of the market and serves to draw attention away from the economic and social disadvantages that result from discrimination and structured forms of inequality ${ }^{38}$. Siguiendo a Marx, Scott señala que la extensión de la emancipación a grupos previamente excluidos de ella no altera las estructuras de dominación y la desigualdad. Por el contrario, naturaliza dichas estructuras, relegándolas al ámbito de la sociedad civil y despojándolas de su carácter político ${ }^{39}$. En este sentido, la sexualidad liberada sublima el lema feminista: "lo personal es político». En el siglo XXI la frontera entre lo público y lo privado desaparece y las mujeres de Occidente son representadas como sexualmente liberadas. Identificado este fenómeno como símbolo de la alcanzada igualdad de género, esta se completa con la aceptación de prácticas sexuales diversas. El mercado se adapta a la homosexualidad y hace de ella un negocio lucrativo. Según Scott, la retórica de la democracia que utiliza la emancipación sexual y la convierte en sinónimo de igualdad de género trabaja al servicio del capitalismo global ${ }^{40}$. En relación con esto, Nancy Lindisfarne y Jonathan Neale han identificado tres aspectos vinculados con los cambios que el neoliberalismo ha fomentado en las masculinidades: la naturalización de la desigualdad; el aumento de las diferencias de género; y el de las distancias culturales y físicas entre la élite y la gente común ${ }^{41}$.

36. PuAR, Jasbir K.: Ensamblajes terroristas, op. cit., p. 46.

37. МонаNтy, Chandra Talpade: «Under Western Eyes: Feminist Scholarship and Colonial Discourses», Boundary 2, vol. 12.3 - vol. 13.1, 1984, pp. 333-358.

38. Sсотт, Joan W.: Sex and secularism, Nueva Jersey, Princeton University Press, 2017, p. 159.

39. Ibídem, pp. 172-173.

40. Ibídem, p. 75.

41. Lindisfarne, Nancy y Neale, Jonathan: «Masculinities and the lived experience of neoliberalism». En: Cornwall, Andrea, Karioris, Frank G. y Lindisfarne, Nancy (eds.): Masculinities under neoliberalism, Londres, Zed Book, 2016, pp. 29-50. 
En Los blancos estáis locos la masculinidad homonormativa de los protagonistas se define especialmente por contraposición con la feminidad de la mujer guineana, simbolizada en la figura de su criada. Yolanda trabajaba para el personal de la embajada antes de que el matrimonio Melgar-Martín llegara a Guinea. Había sido instruida por la mujer de un trabajador de la embajada en cómo realizar las tareas domésticas al gusto de los españoles y es fuente de anécdotas a lo largo de todo el relato. Luis Melgar presta particular atención a su forma de vestir y gestionar el vestido. Asimismo, llama la atención la diferencia en el tratamiento del cuerpo y la estética que el matrimonio Melgar-Martín desarrolla a lo largo del relato — preocupados siempre por la dieta, la forma física y realizar ejercicio en el gimnasio - con respecto al tratamiento del cuerpo y las prácticas deportivas de la masculinidad imperial, descrita anteriormente.

Josep Martí recuerda cómo el cuerpo es un vehículo para la imposición de fuerzas sociales, políticas y económicas a los individuos y también un lugar de resistencia. Siguiendo a Hildi Hendrickson, este autor señala cómo la ropa y otros elementos de la superficie corporal son símbolos clave en las performances a través de las cuales la modernidad es construida y contestada. Desde el punto de vista occidental, la desnudez se vincula con lo salvaje mientras que el vestido se identifica con lo civilizado. Vestir es dotar de dignidad a aquellos que carecen de ella, de ahí las políticas coloniales que regularon de forma estricta el modo de vestir de los pueblos colonizados. La presentación social del cuerpo puede servir asimismo para contrarrestar los discursos raciales sobre la diferencia y reclamar igualdad por parte de los grupos subalternos ${ }^{42}$.

Yolanda, que en casa de los Melgar va siempre descalza, es representada como ingenua, inocente, pobre, inculta, materialista, exagerada, supersticiosa y entrañable, poseedora de una sabiduría que ayuda a sus jefes a relativizar sus propios problemas y mirarse con los ojos del extranjero. No obstante — dado que quiere medrar - el destino de Yolanda es imitar a los blancos. De hecho, el relato de las aventuras de Luis y Pablo, antes de trasladarse a Guinea, comienza curiosamente en El Corte Inglés, concretamente en el servicio que este establecimiento ofrece para los diplomáticos españoles en el exterior. Allí adquieren todo tipo de alimentos y mobiliario que serán enviados más tarde, por vía marítima, en un contenedor a Malabo.

— ¡Chico! ¡Qué lujo! Yo nunca había visto una cosa así. Los blancos tienen muchísimas cosas. Hay máquinas para todo. Quieres un café, lo metes en una máquina y te sale caliente. En la Embajada siempre hay luz, no se corta nunca, y el agua llega a todas las cosas y así te puedes bañar sin tener que ir a por agua a la fuente. Pero lo que más me gusta es la ropa. ¡Chico, los blancos tienen demasiada ropa! Y es ropa buena, de la que reina en Europa, ropa buena. Y teléfonos y gafas de sol y collares y todo. ¡El

42. MarTí, Josep: "África: Cuerpos colonizados, cuerpos como identidades", Revista de Dialectología y Tradiciones Populares, vol. 67.1, pp. 319-346. 
hombre blanco sí que sabe vivir! Yo lo tengo claro, quiero vivir como los blancos, que es mucho mejor ${ }^{43}$.

Así pues, no solo sus jefes, sino las mujeres blancas españolas se presentan como modelos a seguir para Yolanda. De este modo, el personaje de Pilar (Pilar Sánchez Llorente) la entonces jefa del Centro Cultural de España en Malabo, representa la mujer feminista española y moderna que no necesita de los hombres para realizarse ${ }^{44}$. Pilar contrasta con la mayor parte de las mujeres guineanas, deseosas de encontrar un marido. No obstante, como hemos señalado, la homonormatividad no cuestiona la heteronormatividad, sino que la acompaña y refuerza. Así se pone de manifiesto en un pasaje del libro cuando un grupo de amigos de Pablo y Luis, entre los que hay personas españolas y americanas, van a un local nocturno de Malabo donde los hombres heterosexuales acuden para ligar con mujeres guineanas jóvenes con las que mantendrán relaciones sexuales durante un tiempo a cambio de regalos y otras atenciones. En determinado momento de la noche Pilar decide retirarse, según el narrador, por sus principios feministas, mientras que el resto de los miembros del grupo continúa con la juerga sin mayores preocupaciones ${ }^{45}$.

Yolanda no quiere perder la oportunidad de mejorar su nivel de vida y el de su familia y se afana encantada por imitar, incluso, a la madre de Luis Melgar, Coco Valero $^{46}$. No sólo trata de aprender alguna receta de cocina, sino la forma como esta se relaciona supuestamente con su marido.

- Yo voy a aprender de Coco — intervino Yolanda - y voy a hacer como ella con tu padre. Mira, ella dice así: Chico, préstame un dos mil, que ya te lo voy a devolver. Tu padre dice: No, no te lo presto porque te lo vas a quedar. Pero ella dice: Dámelo o me voy a enfadar. Entonces tu padre se lo da y luego viene a pedírselo y ella dice: ¡No!, no te lo devuelvo. ¡Chico, cuánto hablas! ¡Cállate ya! ${ }^{47}$

Yolanda es según Luis Melgar adicta a las compras, especialmente desde que le mostraron la página web y el catálogo de El Corte Inglés. En uno de sus viajes a Madrid, Pablo y Luis reciben el encargo de Yolanda de comprarle "pelo aguacate». El pelo aguacate es muy preciado entre las mujeres guineanas, especialmente el de color

43. Melgar, Luis: Los blancos estáis locos. Un diplomático español en Guinea Ecuatorial, Barcelona, Ediciones Península, 2017, pp. 71-72.

44. Ibídem, pp. 60-61.

45. Ibídem, pp. 230-234.

46. Coco Valero, madre de Luis Melgar, trabajó como periodista para Televisión Española. A finales de los años sesenta viajó en diversas ocasiones a la Guinea Española con el equipo de Televisión Española encargado de poner en marcha una televisión guineana y formar a personal técnico. Resulta significativo que Luis Melgar no tuviera conocimiento de la relación entre su madre y la colonia hasta que esta viajó a Guinea Ecuatorial, para visitarlo, cuarenta años después, según manifiesta en el libro.

47. Melgar, Luis: Los blancos estáis locos, op. cit., p. 100. 
negro azabache. Este pelo natural se vende en la Calle Aguacate de Madrid y procede en ocasiones de países como India o China. La falta de contexto histórico permite naturalizar las diferencias "raciales», de género y clase así como las relaciones de poder coloniales que simboliza la cuestión del pelo. El pelo natural de las mujeres afrodescendientes posee una gran carga simbólica, ya que ha sido y es identificado en el contexto de supremacía blanca como signo de inferioridad racial, como un pelo "malo", sucio, feo que hay que domeñar con químicos o sustituir por pelucas para poder alcanzar ciertos ideales de belleza, occidentales. Lucir el pelo afro natural se torna asimismo en símbolo de resistencia y es dotado de significación política por muchas personas racializadas.

Sin entrar en mayores discusiones, llamé a Pablo para que le diéramos a Yolanda las cosas que le habíamos traído de España. La medicina de Dieguito, por supuesto, ropa de Zara, un bolso, zapatos... y una maleta llena de pelo. Las demás cosas le hicieron ilusión, pero al ver el pelo casi se desmaya.

— ¿Chico! ¿Y cuánto os ha costado? Aquí cada mata de pelo cuesta un cincuenta mil. Voy a poner un puesto en el Semu y voy a tocar bien de dinero ${ }^{48}$

El interés de Yolanda por el pelo azabache o la actitud de algunas mujeres guineanas en relación con los hombres europeos blancos podría haberse conectado con el orden racista colonial y, en este último caso, con la voluntad de Yolanda de subir algún escalafón en la jerarquía social. Yolanda, quizás por su talante personal, y como consecuencia de su interrelación con el matrimonio homosexual blanco y pudiente, subvierte poco a poco algunas de las tradiciones bubis, que son explicadas de forma amena y divertida. Así, Yolanda decide acortar el tiempo del luto tradicional tras el fallecimiento de su pareja. Yolanda, a diferencia de otras mujeres guineanas, no quiere depender de ningún hombre. «-Yo voy esta tarde a ponerme aguacate. Me da igual lo que digan las vecinas. No me voy a quedar un año en casa llorando por el tonto ese ${ }^{49}$.

A su paso por el complejo de la embajada española, Yolanda se moderniza a través de varios mecanismos: el contacto con sus jefes españoles que la proveen de bienes materiales y de un sueldo superior a la media del país; la influencia de las mujeres españolas, especialmente de la madre del autor; y la participación en el consumo de bienes del mercado procedentes de occidente. Cabe recordar aquí, con Andrea Cornwall, cómo el énfasis del discurso neoliberal en la necesidad del individuo de conducirse y gestionar su vida como un "yo emprendedor", va de la mano de la despolitización de las diferencias y la naturalización de las desigualdades sociales a las que nos referíamos más arriba ${ }^{50}$. Es desde este punto de vista que Yolanda, en su proceso emancipador y modernizador, es representada como una auténtica emprendedora:

48. Ibídem, p. 124

49. Ibídem, p. 163

50. CoRnWAll, Andrea: "Introduction: masculinities under neoliberalism», op. cit., pp. 11-12. 
Mientras Guinea se debatía entre la CAN y otros acontecimientos de escala mundial, Yolanda seguía feliz en su microcosmos rebolano. Disfrutaba cada vez más de su soltería y de su independencia. Tenía su trabajo y su bar, y entre ambos, lograba dinero más que suficiente para vivir y para seguir adelante con la construcción de su casa, que iba equipando poco a poco con un congelador, un televisor de plasma, una aspiradora y otros aparatos propios de la modernidad que, o bien compraba ella misma en los distintos mercados locales, o bien nos encargaba a Pablo y a mí para que se lo trajera alguno de nuestros frecuentes visitantes ${ }^{51}$.

Este proyecto de emprendeduría, al que se somete por iniciativa propia Yolanda, bajo la influencia de los Melgar, representa la emancipación de la mujer, identificada con la igualdad de género, y con el camino de la modernidad. Guinea puede seguir esta senda de la mano de su antigua metrópoli, que en este discurso se sitúa en una posición de superioridad. La figura antagonista de Yolanda en el relato de Luis Melgar es Margarita Roka, una mujer bubi doctora en medicina, que posee la nacionalidad española y realizó sus estudios en España. Margarita Roka es una mujer religiosa (monja) y también una mujer de ciencia: se encarga de realizar las pruebas de diagnóstico de la malaria que resultan fundamentales en el país para mantener la salud y combatir el paludismo. Frente a la superstición y la irracionalidad, Luis y Pablo se identifican con la racionalidad y la ciencia, que simboliza su amiga Margarita Roka, ya «totalmente modernizada", tras su paso por España.

En relación con la «excepcionalidad de género», que atraviesa el discurso sobre la modernidad occidental, se haya otra cuestión que fascina a los españoles: la poligamia en Guinea Ecuatorial. Este tema interesa mucho a Luis Melgar, que lo trata en diversos capítulos del libro para señalar el contraste entre su propia relación de pareja homosexual y monógama con la de otros miembros del gobierno guineano que mantienen relaciones heterosexuales polígamas. La poligamia es así otro elemento que señala la diferencia respecto a la sociedad española (occidental y moderna), y prueba de la ausencia de igualdad de género y el retraso de la sociedad ecuatoguineana ${ }^{52}$.

Un número significativo de estados africanos persiguen las relaciones consentidas entre adultos del mismo sexo y ejercen la homofobia de Estado, en contextos donde las minorías sexuales son a menudo víctimas de crímenes de odio. La estancia del matrimonio Melgar-Martín en Guinea Ecuatorial finaliza con la organización en el Centro Cultural de España de la I Semana de Expresión Cultural LGTB de Guinea Ecuatorial. Se trató de la primera iniciativa de ese tipo llevada a cabo en Guinea y

51. Ibídem, p. 265.

52. La identificación entre monogamia y modernidad es histórica. De hecho, las relaciones poliamorosas son identificadas en occidente como una práctica moderna. Una perspectiva diferente sobre la poligamia en Guinea Ecuatorial puede encontrarse en la novela de: MekuY, Guillermina: Tres almas para un corazón, Madrid: Planeta, 2005. 
pretendía normalizar las relaciones homosexuales y a las personas LGTBI+ en Guinea. Luis Melgar aprovechó que dirigía interinamente el Centro Cultural para impulsar esta iniciativa, con el apoyo del Ministerio de Asuntos Exteriores de España y la Agencia Española de Cooperación Internacional (AECI), Amnistía Internacional, así como de numerosos colectivos LGTBI españoles. Para su celebración, el Centro Cultural contó además con el apoyo de otras embajadas occidentales con sede en Guinea Ecuatorial como las de Estados Unidos, Alemania o Francia.

En el marco de ese evento, el Centro Cultural de España acogió la exposición "Amar no es un delito", así como a diversos activistas LGTBI procedentes de España y también guineanos, como la escritora Trifonia Melibea Obono, que dieron charlas y organizaron talleres. ${ }^{53}$ Educar a los africanos en el respeto a la diversidad sexual aparece de este modo vinculado en la actualidad con la modernidad de naciones como la española y obvia el hecho de que el modelo heteronormativo de relaciones sexuales fue exportado e impuesto por la colonización europea. Siguiendo el ejemplo de otros países, Luis Melgar cofundó en mayo de 2019 la asociación "Exterior es diverso", creada por el Ministerio de Asuntos Exteriores, Unión Europea y Cooperación de España para dar visibilidad y apoyo a las familias LGTBI del Servicio Exterior español. ${ }^{54}$ Estas familias se encuentran a menudo destinadas en países donde las relaciones homosexuales no son reconocidas legalmente o son castigadas incluso con la pena de muerte. Esta asociación fue presentada en Madrid en la Escuela Diplomática en 2017. Los derechos LGTBI son prioritarios en la actividad diplomática española y forman parte de la política exterior de derechos humanos española. España posee buena reputación en el ámbito internacional en relación con los derechos LGTBI debido a que la Ley del matrimonio homosexual — aprobada en 2005 bajo el gobierno de José Luis Rodríguez Zapaterofue una de las primeras en el mundo y fue bien recibida por la gran mayoría de la población. Aunque el programa "España Global» del Ministerio de Asuntos Exteriores — sustituto de la antigua "Marca España»— no menciona explícitamente los derechos LGTBI, pretende afianzar la imagen de España en el exterior como una democracia plena y defensora de los Derechos Humanos, y como un Estado «sólido y solidario; rico y diverso: flexible y abierto al cambio". Este programa tiene por objetivo "atraer un mayor número de inversiones productivas, facilitar la internacionalización de las empresas y potenciar el sector exportador de bienes y servicios; atraer un mayor número de investigadores, académicos y turistas; así como tener una mayor presencia en los

53. Trifonia Melibea Obono se ha declarado abiertamente lesbiana. Su novela La bastarda está prologada por Luis Melgar. Véase: OBono, Trifonia Melibea: La bastarda, Madrid: Flores Raras, 2016.

54. Véase la nota de prensa 082 del Ministerio de Asuntos Exteriores, Unión Europea y Cooperación, "Presentación de 'Exterior es Diverso'", plataforma LGBTI del Servicio Exterior español», 17 de mayo de 2019: [http://www.exteriores.gob.es/Portal/es/SalaDePrensa/NotasDePrensa/Paginas/2019_NOTAS_P/20190517_ NOTA082.aspx] Consultada el 15 de abril de 2020 
diferentes foros internacionales de toma de decisiones» ${ }^{55}$. La plataforma "Exterior es diverso" del Ministerio de Asuntos Exteriores, Unión Europea y Cooperación de España contribuye a reforzar los objetivos del programa «España Global» y la imagen de España como una nación moderna, respetuosa con los Derechos Humanos. Los derechos de las parejas homosexuales se solaparían así con políticas internacionales fuertemente vinculadas con el neoliberalismo.

\section{Conclusiones}

A lo largo de la última década, el debate sobre la modernidad de la nación española se ha dirimido, entre otros ámbitos, en el de las relaciones de España con su antigua colonia Guinea Ecuatorial. En este debate, la nación española ha sido representada de manera masculina frente a Guinea, que ha sido a menudo feminizada, en el marco de un discurso sobre la modernidad española que necesita compararse con su antiguo Otro para enfatizar su carácter moderno y civilizador. En esos debates, la nación ha sido representada a través de distintas masculinidades que se encuentran en tensión. El modelo heteronormativo del explorador, identificado con la masculinidad colonial/ imperial, convive con un modelo homonormativo que se presenta como más sofisticado. No obstante, ambos se enmarcan en una teoría sobre la modernidad española y están atravesados por un marco interpretativo desarrollista y por una concepción lineal y evolutiva de la historia que reproduce las lógicas coloniales. El modelo de masculinidad imperial está representado por un hombre blanco, heterosexual, fuerte, valiente, aventurero, capaz de dominar la naturaleza y que representa la avanzadilla de la civilización, que se sustancia en la sanidad y la educación occidentales. El explorador interpreta África y la Guinea Española de la época colonial como una mujer bella aunque peligrosa, que debe ser conquistada. Los pueblos africanos, identificados con la naturaleza dominada por los colonos, se sitúan en estadios de desarrollo inferiores a los de los españoles.

El modelo de masculinidad homonormativa, por el contrario, se identifica con hombres cultos, delicados, caritativos, sofisticados, cosmopolitas, diplomáticos, aventureros, preocupados por su apariencia, consumistas. Este ideal de masculinidad convive con el modelo de masculinidad del explorador y refuerza el sistema que sitúa aquella categoría en una posición de privilegio frente a otras feminidades. Este modelo homonormativo, al igual que el arquetipo del explorador heterosexual, se define en oposición a otras masculinidades y feminidades y, especialmente, frente a la feminidad subordinada de la mujer guineana pobre e inculta, la «mujer del tercer mundo».

55. Ministerio de Asuntos Exteriores, Unión Europea y Cooperación. «España Global». [http://www. exteriores.gob.es/Portal/es/PoliticaExteriorCooperacion/MarcaEsp/Paginas/Inicio.aspx] Consultada el 15 de abril de 2020 . 
La emancipación de las mujeres racializadas y la forma en que los hombres racializados se relacionan con ellas constituye una obsesión en el discurso orientalista europeo. Desde el punto de vista del discurso de la modernización, la sumisión de estas mujeres constituye una prueba del atraso de sus pueblos. En este escenario, la emancipación de las mujeres guineanas, la poligamia y la igualdad de género se utilizan como elementos que marcan la diferencia entre una España moderna y una Guinea Ecuatorial que representa al Tercer Mundo. El destino de los ecuatoguineanos es imitar a los españoles y especialmente participar del mercado neoliberal y la cultura del consumo que nos identifica no como ciudadanas sino como consumidoras y potenciales emprendedoras. La visibilización y defensa de los colectivos LGTBI como prioridad en la política exterior española constituye un ejemplo del mencionado pinkwhasing. Esta política está al servicio de la creación de una imagen moderna de España en el ámbito internacional que pretende atraer inversores y turistas. Hemos comprobado cómo los discursos sobre el género y la masculinidad analizados naturalizan y despolitizan diferencias que no pueden ser explicadas al margen de las lógicas coloniales que atraviesan el orden postcolonial y dan sentido a nuestras sociedades. Una mirada crítica y decolonial, que deconstruya los modos en que género, nación, clase y «raza» se entretejen, resulta indispensable para estudiar los imaginarios nacionales y de género que construyen en el presente la nación española. 